\title{
THE RELATIONSHIP BETWEEN INSENSIBLE WATER LOSS AND HEAT PRODUCTION IN PATIENTS WITH HYPOTHYROIDISM COMPARED WITH NORMAL SUBJECTS ${ }^{1}$
}

\author{
By D. ROURKE GILLIGAN AND GEOFFREY EDSALL \\ (From the Medical Research Laboratories of the Beth Israel Hospital and the Department of \\ Medicine, Harvard Medical School, Boston)
}

(Received for publication June 6, 1935)

In normal subjects in the basal state the heat lost from the body through evaporation of water from the skin and respiratory passages has been found to be related to the total heat production. Soderstrom and DuBois (1) in 1917 measured the basal heat production and the water of vaporization from the body simultaneously in a Russell-Sage calorimeter; 27 studies in 12 normal male subjects, 20 to 50 years of age, revealed that an average of 24 per cent, with variations from 21 to 28 per cent, of their total heat production was expended in the vaporization of water. Studies in 8 boys and 6 old men showed an average of 27 per cent of the total heat lost through vaporization in each group (1). Subsequently, Levine and Wilson (2) found that infants and children lost in this manner an average of 26 per cent of their heat production. Benedict and Root (3) in 1926 measured the basal metabolic rate and either the basal or sleeping insensible water loss in a large group of individuals comprising normal subjects and patients with diabetes or thyrotoxicosis; from their data these authors constructed. a table for predicting metabolism from the basal or sleeping insensible weight loss. The studies of Benedict and Root (3) and those of subsequent investigators $(4,5,6$, and others) confirm in general those of Soderstrom and DuBois in normal subjects. On the basis of data available in the literature $(1,2,6)$ Lavietes (7) has recently described an average relationship between basal insensible loss of weight and basal heat production in normal subjects by the equation: Calories (per hour) $=2.2 I L$, where $I L$ represents the insensible weight loss in grams per hour.

Attempts to correlate insensible water loss with metabolism under conditions other than basal have yielded varying results. It has been found that

1 This investigation was aided by a grant from the William W. Wellington Research Fund of Harvard University. the insensible weight loss increases above the basal when a patient assumes the sitting position (8), on activity $(9,10)$, in fever (1), and usually after eating $(1,11,12)$. Jores (11) and Dieckhoff (12), however, found that the increase in metabolism following a protein meal was not always associated with a corresponding increase in insensible water loss, in fact in certain experiments the insensible loss did not increase at all when the metabolism increased by as much as $\mathbf{3 0}$ per cent. Furthermore, results of other investigators have revealed that the heat lost by vaporization in sleep $(8,9,13)$ and on activity $(7)$, even when unaccompanied by sensible perspiration, may not bear the same relation to total heat production as obtains under basal conditions.

To what extent the percentage of the total heat lost by water vaporization varies in metabolic diseases which alter heat production is not entirely clear. Thus, although the percentage of heat lost by vaporization in hyperthyroidism has been studied by several authors, studies in only a few isolated cases of hypothyroidism are reported. The percentage of the total heat lost through vaporization under basal conditions has often been found increased in hyperthyroidism $(1,3,4,11)$, even when no sensible perspiration is discernible; the few available reports in hypothyroidism indicate that the percentage heat lost through vaporization may be less than normal $(1,4,9)$. The purpose of the present investigation was to determine the relationship of insensible water loss to heat production in a group of patients with hypothyroidism. By comparing the values in hypothyroidism with values in normal individuals under. identical experimental conditions, certain differences became evident.

\section{MATERIAL AND METHODS}

Nine studies were made in eight patients with hypothyroidism which developed following total ablation of 
the thyroid gland, performed for the relief of either angina pectoris or congestive heart failure (14). Some clinical signs and symptoms of hypothyroidism were present in all these patients at the time of study. In accord with considerations outlined elsewhere (14), thyroid (Armour's) medication was being administered to three of the patients in amounts sufficient to prevent distressing symptoms of myxedema (Table I). A few patients were studied just before thyroid therapy was started, when striking clinical manifestations of myxedema were present. Two additional studies were made in two of the patients with hypothyroidism after the metabolic rate had been increased by the administration of dinitrophenol for several days before the test. The results in the patients with hypothyroidism are compared with those obtained in eleven studies in nine individuals with no evidence of endocrine disease; seven of these tests were made in five individuals who were entirely normal; the diagnoses in the other four patients are given in Table $\mathrm{I}$.

The experiments were done either after the patient had fasted over night or three hours after he had eaten a light breakfast $(200 \mathrm{cc}$. of orange juice and a slice of toast with butter), consisting mainly of carbohydrate. After coming to the laboratory he removed his clothes and put on a hospital Johnny, outing flannel pants and cotton socks, thus covering the whole body except the hands and face. These clothes were hung in the laboratory for several hours and were weighed just before they were donned. The laboratory temperature was adjusted and controlled between $73^{\circ}$ and $78^{\circ} \mathrm{F}$.

A Troemner 2 "human being balance" with suspended seat was utilized for weighings. This balance in our hands appeared accurate to approximately $1 \mathrm{gram}$; although the weight measurements are not as exact as those obtainable with a more sensitive balance, they serve for the purpose of this investigation. The subject sat in the balance seat for at least 30 minutes, after which a metabolic rate measurement was made, the expired gases being collected for ten minutes in a Tissot spirometer. The weight of the patient was then taken, the time being noted exactly. The patient remained quiet on the balance during the following hour, after which another weight measurement was made. The metabolic rate measurement was then immediately repeated. Following this the patient stepped directly from the balance to a bed where measurements of the skin temperature at twenty-five points on the body, including points on the head, trunk, and both left and right extremities, were made with a standard thermocouple. The clothes were removed and immediately reweighed; in almost every instance the weight increased from 0 to 3 grams, the average gain being approximately 2 grams. Although there was an appreciable gain in the weight of the clothes as thus measured it is probable that equilibrium was obtained with the cutaneous water loss and the atmosphere during the hour which elapsed between dress-

2 Obtained from Henry Troemner, Philadelphia, Pa. ing and the beginning of the weighings to determine the insensible water loss, the change in the weight of the clothes during the hour when the insensible weight loss was measured probably being insignificant (10).

The average deviation from the average of the two metabolic measurements made in each experiment was \pm 2 per cent, the range being from \pm 0 to \pm 5 per cent. The insensible water loss per hour was calculated from the insensible weight loss by subtracting the weight lost through gas exchange (weight of carbon dioxide expelled minus weight of oxygen consumed, this data being obtained from analyses of the gases expired during the measurements of the metabolic rate). The percentage of the total heat lost through water evaporation from the skin and lungs was calculated from the caloric equivalent of the water evaporated (grams water $\times 0.58=\mathrm{cal}$ ories) and the total metabolism. The average volume of the expired gases for the two 10 minute periods in which metabolic measurements were made were utilized to calculate the respiratory minute volumes.

The measurements of basal metabolic rate were made with a Collins-Benedict-Roth apparatus on the day of the measurements of insensible water loss or shortly preceding this date. The Aub-DuBois standards (15) were utilized in calculating the deviation of the basal metabolism from normal.

\section{RESULTS}

The average metabolism of the control subjects on the balance was 65 calories per hour and the average insensible water loss was 33 grams per hour; in the hypothyroid group the average metabolism was 51 calories per hour and the average water loss only 19 grams per hour (Table I). The average basal metabolic rate of the hypothyroid patients was 29 per cent below the standard average normal with variations between minus 23 and minus 44 per cent. In the subjects without hypothyroidism an average of 29 per cent of the total heat produced was eliminated by evaporation through the skin and respiratory passages; in the hypothyroid patients an average of 22 per cent of the heat produced was thus eliminated. Whereas the percentage heat dissipated by evaporation was above 25 per cent in nine of eleven experiments in the control subjects, it was below 25 per cent in seven of the nine experiments in the patients with hypothyroidism. The results in the two hypothyroid patients whose metabolic rates were raised to plus 7 and minus 12 per cent with dinitrophenol were similar to the results obtained in the same patients before the drug was given (Table I). 


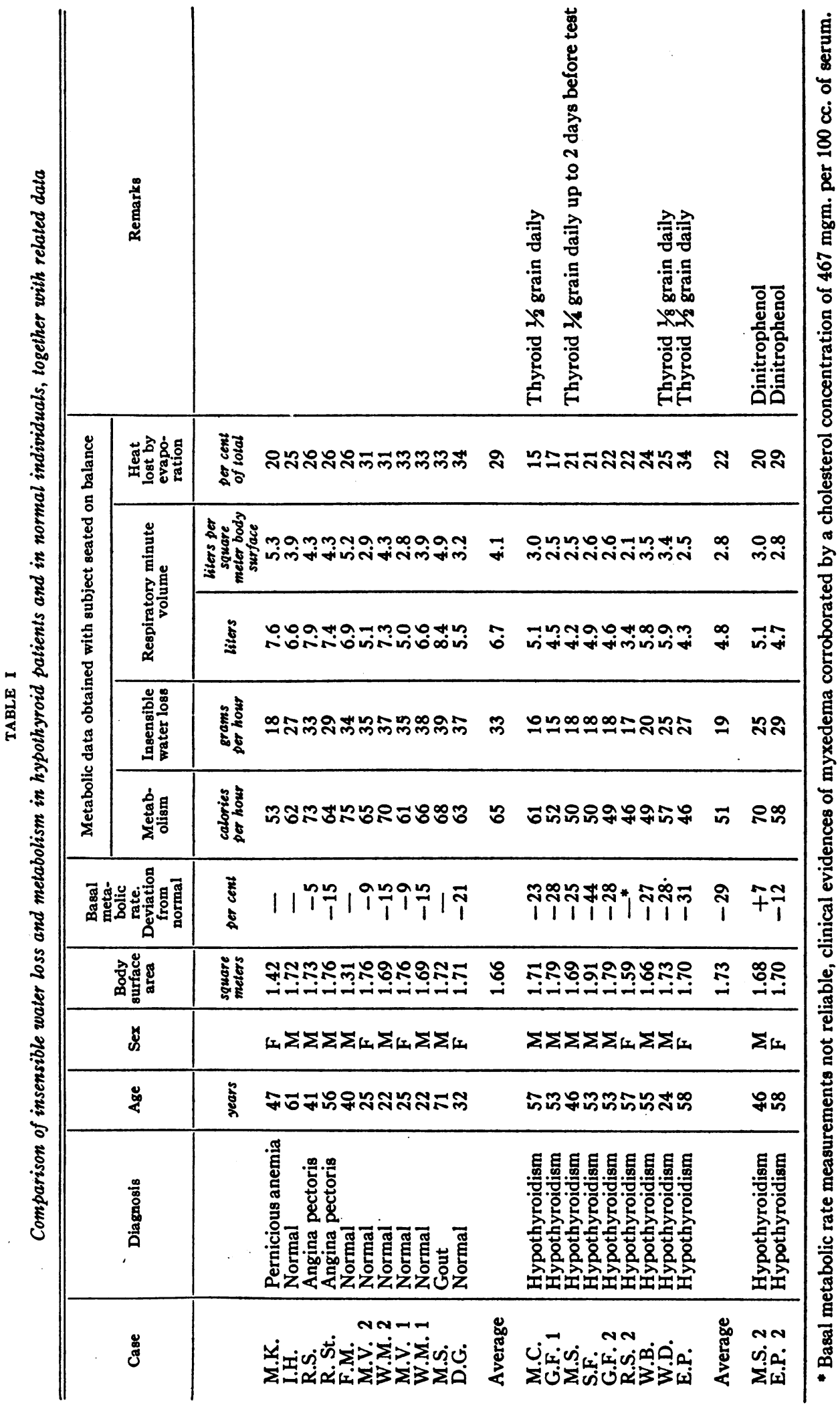


The respiratory minute volume per square meter of body surface was 32 per cent lower in the hypothyroid group than in the control subjects (Table I). In the two groups of subjects the average and the range of variation of skin temperatures were practically the same at all the body sites except in the lower extremities, where the values tended to be slightly lower in the hypothyroid group. In the patients with hypothyroidism the metabolism sitting on the balance averaged 10 per cent higher than the basal metabolism; in five control subjects ( 7 experiments), where the basal metabolic rates were known, the metabolism sitting on the balance averaged 15 per cent higher than the basal.

\section{DISCUSSION}

The foregoing experiments demonstrate that the percentage of the total heat production which is eliminated by water evaporation from the skin and respiratory passages is distinctly lower in patients with hypothyroidism than in normal subjects. These experiments were performed with the subjects sitting upright on a hard surface, and the results are therefore not strictly comparable with those obtained in subjects in the basal state by other investigators; this difference in experimental conditions probably accounts for the somewhat higher average percentage heat loss by evaporation in our. control group than has been found in normal subjects under strictly basal conditions by others $(1,2,6)$. Benedict and Wardlaw (8) in four experiments found the insensible water loss to increase on an average of 20 per cent in the sitting position as compared with the lying position; no simultaneous metabolic measurements were made, but the increase in water loss seemed somewhat higher than the expected increase in metabolism (8).

A few experiments performed under basal conditions in patients with hypothyroidism are reported by other investigators, and our conclusions accord with their results $(1,4,5,9)$. Soderstrom and DuBois (1) found the percentage heat lost by evaporation under basal conditions in four experiments in three dwarfs with symptoms of hypothyroidism (cretins) somewhat less than normal; the values for these four experiments were 20,21 , 21 and 24 per cent heat lost by evaporation, whereas under the same experimental conditions these authors found that normal subjects of the same age lost from 21 to 28 per cent (average 24 per cent) of their heat by evaporation. Magendantz (4) reports one strikingly low percentage heat loss by evaporation in an obese patient with symptoms of myxedema and a basal metabolic rate 30 per cent below the standard average normal; after thyroid treatment the heat lost by this channel was increased. Jores (9) found a markedly diminished percentage heat loss by evaporation from the skin in one myxedematous patient whose basal metabolic rate was 24 per cent below the standard normal; after treatment the water loss by the skin increased to normal also in this instance.

Benedict and Benedict (16) and Jores (9) have shown that in normal individuals under basal conditions approximately 40 per cent of the total water evaporated from the body comes from the respiratory passages. In our experiments the respiratory minute volume of the patients with hypothyroidism averaged 32 per cent lower than that of the control group, and the calories per hour averaged 22 per cent lower (Table I). From these results it is apparent that the volume respiration per unit of metabolism was not significantly different in the hypothyroid subjects than in the control group. ${ }^{3}$ It may be concluded that the decrease in water loss in the respiratory passages in the hypothyroid group was therefore in approximate proportion to the lowering of the metabolism. Since, however, the total percentage heat lost through evaporation was low in the hypothyroid group, it follows that the percentage heat lost through loss of water by the skin must have been markedly below normal. This finding accords with Jores' (9) direct observation of a markedly decreased percentage heat loss by vaporization of water from the skin in one case of myxedema. The lowered loss of water by the skin in our patients with hypothyroidism does not appear to be due to lowered skin temperature; although the average skin temperature of the lower extremities was slightly less than that of the control group, there was no correlation between the skin tempera-

3 The average respiratory volume per calorie was .103 liter in the control group and 0.094 in the hypothyroid group. 
ture and the insensible water loss in individual instances. The abnormal diminution in loss of water by the skin in patients with hypothyroidism may be due to the dryness of the skin in such cases. On the other hand, some other rearrangement may be the essential factor in the lowered loss of water by the skin and the consequent conservation of body heat. In contrast to the abnormally low loss of water by the skin in hypothyroidism, Jores (11) has reported an abnormally high loss from the skin in hyperthyroidism.

The value of an indirect method of measuring total 24 hour metabolism of normal and pathological subjects under conditions of varied activity, i.e. sleep, moderate exercise, eating, talking, reading, etc., is apparent. Newburgh and his co-workers $(17,18)$, Lavietes $(7)$, and others have attempted to apply measurements of insensible weight loss to this purpose. The hypotheses on which the measurement of total 24 hour metabolism by insensible water. loss rest, are: (1) the percentage of the total heat which is lost by evaporation in a given normal or pathological individual in the basal state does not vary appreciably from the average figure for normal individuals; (2) the percentage heat lost by evaporation under conditions of sleep, digestion, moderate activity, etc., does not vary significantly from that under basal conditions; and (3) sensible perspiration does at no time appear. It is apparent from our results that it would be inaccurate to use the same factor for heat lost by evaporation in patients with hypothyroidism and in normal subjects. It appears, moreover, that the factor in both normal and diseased subjects varies to such an extent even under basal conditions $(3,4,9$, and 11) and with the patient sitting quietly (Table I) that the acceptance of an average factor for any group, normal or. pathological, may lead to quite erroneous conclusions. As stated above, there is evidence to indicate that the percentage heat lost by evaporation in sleep, after eating, on activity, etc., is not the same as under basal conditions. There is also evidence that the percentage of the total heat production eliminated by water evaporation may be quite abnormal in obesity $(4,19$, and 20$)$, diseases associated with abnormal water balance (literature reviewed by
Lavietes (7)), hyperthyroidism (1, 4, and 11) and other conditions. Lavietes (7) has reviewed the results of other investigators who have reported measurements of 24-hour metabolism by insensible weight losses and has added observations of his own. His studies illustrate fallacies in the method. From the results of our studies it must be concluded that an empirical relationship between water loss and metabolism based on results found under basal conditions in normal individuals can not be applied to the measurement of metabolism in patients with hypothyroidism. It also seems to the authors that even though the percentage of the total heat production for a given individual were found constant under basal conditions, this value could not be applied with reliability to a measurement of total 24-hour metabolism.

TABLE II

Skin temperature findings

\begin{tabular}{|c|c|c|c|c|}
\hline \multirow{2}{*}{ Body site } & \multicolumn{2}{|c|}{$\begin{array}{l}\text { Average skin } \\
\text { temperature }\end{array}$} & \multicolumn{2}{|c|}{$\begin{array}{l}\text { Limits of skin } \\
\text { temperature }\end{array}$} \\
\hline & $\begin{array}{c}\text { Con- } \\
\text { trol* } \\
\text { group }\end{array}$ & $\begin{array}{c}\text { Hypo- } \\
\text { thyroid } \\
\text { group }\end{array}$ & $\begin{array}{c}\text { Con- } \\
\text { trol } \\
\text { group }\end{array}$ & $\begin{array}{l}\text { Hypothy- } \\
\text { roid } \\
\text { group }\end{array}$ \\
\hline 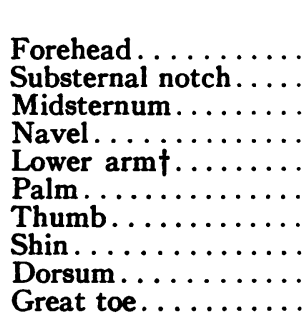 & $\begin{array}{c}\circ C . \\
32.4 \\
32.5 \\
32.9 \\
33.1 \\
32.6 \\
32.0 \\
30.4 \\
31.4 \\
30.7 \\
28.3\end{array}$ & $\begin{array}{l}\bullet C . \\
32.2 \\
32.5 \\
32.4 \\
32.5 \\
32.0 \\
31.6 \\
30.3 \\
31.0 \\
29.4 \\
27.4\end{array}$ & \begin{tabular}{|c|}
${ }^{\circ} C$. \\
$31.6-33.5$ \\
$31.4-34.0$ \\
$31.9-34.3$ \\
$32.5-35.0$ \\
$31.5-34.5$ \\
$30.7-34.3$ \\
$27.5-32.6$ \\
$30.2-32.7$ \\
$28.6-33.5$ \\
$26.1-32.1$
\end{tabular} & $\begin{array}{c}\bullet C . \\
31.4-32.9 \\
30.7-34.8 \\
31.7-33.2 \\
31.1-34.2 \\
30.6-33.3 \\
28.1-32.9 \\
26.8-32.5 \\
30.5-31.6 \\
27.3-31.1 \\
24.6-30.3\end{array}$ \\
\hline
\end{tabular}

* There were 9 experiments in 8 control subjects, and 7 experiments in 6 subjects with hypothyroidism.

†The temperatures recorded for the extremities represent the average of the mean findings for the two limbs.

\section{SUMMARY}

The insensible water loss and the metabolism in the sitting position have been measured in patients with hypothyroidism following total thyroidectomy and, under identical experimental conditions, in normal individuals. The insensible water loss was found strikingly decreased in hypothyroidism, and the percentage of the total heat lost by water evaporation in the hypothyroid patients was usually much less than in the normal subjects. Cal- 
culations indicate that the water lost through the lungs in the patients with hypothyroidism was diminished approximately in proportion to the diminished metabolism; the water lost through the skin on the other hand was diminished markedly out of proportion to the lowered metabolism. The pitfalls encountered in attempts to estimate total metabolism by measuring insensible perspiration are discussed; it is concluded that the results of metabolism studies, so made, are subject to unpredictable errors.

\section{BIBLIOGRAPHY}

1. Soderstrom, G. F., and DuBois, E. F., Clinical calorimetry. XXV. The water elimination through skin and respiratory passages in health and disease. Arch. Int. Med., 1917, 19, 931.

2. Levine, S. Z., and Wilson, J. R., Respiratory metabolism in infancy and in childhood. VII. Elimination of water through the skin and respiratory passages of infants. Am. J. Dis. Child., 1928, 35, 54.

3. Benedict, F. G., and Root, H. F., Insensible perspiration: Its relation to human physiology and pathology. Arch. Int. Med., 1926, 38, 1.

4. Magendantz, $H$., Uber die Beziehungen zwischen Perspiratio insensibilis und Grundumsatz bei Gesunden und Kranken. Deutsches Arch. f. klin. Med., 1932, 173, 44.

5. Jores, A., Wie weit stimmen Grundumsatz und Perspiratio insensibilis nach der Benedict-Rootschen Voraussage miteinander ueberein? Klin. Wchnschr., 1932, 11, 2065.

6. Heller, H., and Schwarz, A., Extrarenale Wasserausscheidung und Stoffwechsel. II. Die Verhältnisse bei Unsatzsteigerungen. Ztschr. f. d. ges. exper. Med., 1930, 71, 416.

7. Lavietes, P. H., The metabolic measurement of the water exchange. J. Clin. Invest., 1935, 14, 57.

8. Benedict, F. G., and Wardlaw, H. S. H., Some factors determining the insensible perspiration of man. Arch. Int. Med., 1932, 49, 1019.
9. Jores, A., Perspiratio insensibilis. I. Mitteilung. Ztschr. f. d. ges. exper. Med., 1930, 71, 170.

10. Levine, S. Z., Wilson, J. R., and Kelly, M., The insensible perspiration in infancy and in childhood. I. Its constancy in infants under standard conditions and the effect of various physiologic factors. Am. J. Dis. Child., 1929, 37, 791.

11. Jores, A., Perspiratio insensibilis. III. Mitteilung. Ztschr. f. d. ges. exper. Med., 1931, 77, 734.

12. Dieckhoff, J., Perspiratio insensibilis und spezifischdynamische Eiweisswirkung. Ztschr. f. klin. Med., 1932, 120, 1.

13. Benedict, F. G., and Carpenter, T. M., The metabolism and energy transformations of healthy man during rest. Carnegie Institution of Washington, 1910. Publication No. 126.

14. Blumgart, H. L., Berlin, D. D., Davis, D., Riseman, J. E. F., and Weinstein, A. A., Total ablation of thyroid in angina pectoris and congestive failure. XI. Summary of results in treating seventy-five patients during the last eighteen months. J. A. M. A., 1935, 104, 17.

15. Aub, J. C., and DuBois, E. F., Clinical calorimetry. XIX. The basal metabolism of old men. Arch. Int. Med., 1917, 19, 823.

16. Benedict, F. G., and Benedict, C. G., Perspiratio insensibilis: Ihr Wesen und ihre Ursachen. Biochem. Ztschr., 1927, 186, 278.

17. Newburgh, L. H., Wiley, F. H., and Lashmet, F. H., A method for the determination of heat production over long periods of time. J. Clin. Invest., 1931, 10, 703.

18. Johnston, M. W., and Newburgh, L. H., The determination of the total heat eliminated by the human being. J. Clin. Invest., 1930, 8, 147.

19. Heller, H., Studien über Perspiratio insensibilis. III. Die quantitativen Beziehungen zwischen Perspiratio insensibilis und Energieumsatz. Ztschr. f. d. ges. exper. Med., 1932, 83, 128.

20. Wang, C. C., Strouse, S., and Andersch, M., Metabolism of obesity. VIII. Basal metabolism and insensible perspiration during a period of reducing weight. Arch. Int. Med., 1930, 46, 1002. 